\title{
Sexual experience did not affect the long-term sexual behavior inhibition of male rats treated with fluoxetine
}

\author{
Soraya F. Habr, Renata G. Dias, Elizabeth Teodorov and Maria. M. Bernardi \\ Universidade Paulista, São Paulo, Brazil and Universidade de São Paulo, Brazil
}

\begin{abstract}
Antidepressants, including tricyclics, monoamine oxidase inhibitors and selective serotonin reuptake inhibitors cause sexual dysfunctions such as decreased sexual desire, erectile difficulties, and delayed ejaculation. Studies have shown that treatment with fluoxetine inhibits several components of sexual behavior in male rats. It is known that sexual experience improves the sexual behavior of male rats. Thus, the effects of sexual experience were examined in male rats during long-term treatment with fluoxetine or vehicle. Rats treated with $10 \mathrm{mg} / \mathrm{kg}$ fluoxetine or vehicle daily (28 days) were observed for sexual behavior at the 14th, $21 \mathrm{st}$, and 28th day of treatment. Long-term administration of fluoxetine increased the mount latency in control rats in the first session; no differences were observed in other parameters on the same day. Still in the control group, the mount and intromission latencies gradually decreased, whereas the number of intromissions and ejaculations increased over the sessions. The group in long-term treatment with fluoxetine also showed reduced mount and intromission latencies, although latencies remained significantly higher as compared to the control group. Fluoxetine-treated rats showed increased mount and intromission rates on the 28th day of treatment in relation to the first day. These data suggest that the impairment caused by long-term treatment with fluoxetine persists throughout the sessions despite the rats' sexual experience. Keywords: fluoxetine, sexual experience, heterosexual behavior, rats.
\end{abstract}

Received 28 October 2008; received in revised form 15 December 2008; accepted 27 February 2009. Available online 29 June 2009

\section{Introduction}

Sexual dysfunction can be either a symptom of depressive illness or a side-effect of medications used to treat it. Antidepressants have been implicated in such sexual dysfunctions as decreased sexual desire, erectile difficulties, and delayed ejaculation (Ahlenius, Heimann, \& Larsson, 1979; Frank, Hendricks, \& Olson, 2000; Madeo et al., 2008; Montejo, Llorca, Izquierdo, \& Rico-Villademoros, 2001; Taylor, Weiss, \& Komitowsky, 1983; Vega-Matuszcyr, Larsson, \& Eriksson, 1998; Yells, Prendergast, \& Hendricks, 1992; Yells, Prendergast, Hendricks, \& Miller, 1995).

The tendency of a particular antidepressant agent to cause sexual dysfunction is probably related to the drug's specific mechanism of action. All serotonergic, dopaminergic, and cholinergic-adrenergic

Soraya F. Habr, Renata G. Dias, Elizabeth Teodorov and Maria. M. Bernardi - Instituto de Ciências da Saúde, Universidade Paulista, São Paulo, Brazil. Departamento de Patologia, Faculdade de Medicina Veterinária e Zootecnia, Universidade de São Paulo, São Paulo, Brazil. Correspondence regarding this article should be directed to Maria. M. Bernardi, Departamento de Patologia da Faculdade de Medicina Veterinária e Zootecnia da Universidade de São Paulo. Av. Prof. Dr. Orlando Marquês de Paiva, 87- São Paulo - SP- Brazil, 05508-900. Tel: +55-11-3091-1409. E-mail: marthabernardi@gmail.com neurotransmitter systems have been implicated in sexual dysfunction, as well as the limbic system and specific hormones (Agmo, 1976). Specifically, an increase in central serotonin activity, obtained by the administration of the serotonin precursor 5-hydroxytryptamine (Ahlenius, Heimann, \& Larsson, 1979) or a monoamine oxidase inhibitor (Ahlenius et al., 1971; Tagliamonte, Tagliamonte, \& Gessa, 1971) is accompanied by depression in the sexual behavior ofmale rats. Conversely, a reduction in the brain serotonergic neurotransmission, obtained by the inhibition of tryptophan hydroxylase (Tagliamonte, Tagliamonte, Gessa, \& Brodie, 1969) or chemical or mechanical lesions of serotonin neurons (Da Prada, Carruba, O’Brien, Saner, \& Pletscher, 1972), facilitates this behavior.

Reliable estimates on the actual incidence of sexual dysfunction during treatment with selective serotonin reuptake inhibitors (SSRIs) are difficult to obtain because patients and physicians are reluctant to discuss sexuality (Balon, 2006). As a result, it is still unclear whether subjects affected by depression and with premature ejaculation are impaired in other domains of sexual function as a result of the treatment with SSRIs, and whether different SSRIs have a different impact on male sexuality (Madeo et al., 2008; Montejo et al., 2001; Montgomery, Baldwin, \& Riley, 2002). Data about SSRIs are contradictory. Patterson (1993) reports the 
frequency of sexual side-effects in patients medicated with SSRIs as being lower than $2 \%$, while subsequent studies have shown that sexual dysfunction in patients using SSRIs is considerably more frequent (Althof et al., 1995; Madeo et al., 2008). According to MontejoGonzales et al. (1997) only $14 \%$ of subjects treated with SSRIs spontaneously reported having sexual dysfunctions, but this percentage increases up to $58 \%$ when a specific query on sexual function is provided.

Such sexual side-effects affect the quality of life and may result in poor treatment compliance and the associated risk of relapse. In addition, depression may be associated with sexual disturbances, especially reduced libido (Waldinger \& Olivier, 1998).

Fluoxetine (FLX) is an SSRI used to treat major depressive disorder, bulimia nervosa (an eating disorder), obsessive-compulsive disorder, panic disorder, and premenstrual dysphoric disorder (Dannon et al., 2007; Gamaro, Prediger, Lopes, Bassani, \& Dalmaz, 2008; Gartlehner et al., 2008; Hay, 2007). Furthermore, it is an adjunct to other strategies to treat obese individuals, as it causes weight loss both in laboratory animals and humans (Leombruni et al., 2008; Mancini \& Halpern, 2006; Mitchell, Zwaan, \& Roerig, 2003). However, the mechanisms underlying the effects of FLX in feeding behavior are affected by factors such as stress and hunger (Hsiao, Chung, Tong, \& Cheng, 2006; Gamaro et al., 2008; Placidi et al., 2004).

The FLX antidepressant effects are typically obtained after 2-4 weeks of treatment. Thus, the effects of chronic administration are interesting from both the theoretical and practical perspectives. Studies have shown that treatment with FLX in rats inhibited several components of sexual behavior related to motivation (Ahlenius et al., 1979; Althof et al., 1995; Balon, 1995; Baum \& Starr, 1980, Mendels, Camera, \& Sikes, 1995; Segraves, Saran, Segraves, \& Maguire, 1993; Taylor et al., 1996; Vega-Matuszcyk et al., 1998). In female rats, the sub-chronic treatment with FLX attenuates the effects of acute FLX on sexual behavior (Sarkar, Hiegel, Ginis, Hilbun, \& Uphouse, 2008), induces modest effects on estrous cyclicity and sexual behavior in Sprague Dawley rats (Maswood, Sarkar, \& Uphouse, 2008) and disrupts food intake and estrous cyclicity in Fischer rats (Uphouse, Hensler, Sarkar, \& Grossie, 2006). In male rats, it reduces sexual motivation (VegaMatuszcyk et al., 1998) and copulatory behavior (Frank et al., 2000). For men, the most commonly reported problem is delayed ejaculation or difficulty to ejaculate, as well as some reports on reduced libido (Balon, 1996; Madeo et al., 2008; Montejo et al., 2001).

The sexual behavior of the male rat is composed by a sequence of appetitive responses that bring males into the proximity of females and consummatory responses such as the pursuit of females, mounting, and vaginal intromissions that lead to ejaculation (Sachs \& Meisel, 1988; Toates,
1986). The mount latency is a measure of sexual motivation. The same is valid for the intromission latency but, in this case, it requires penile erection and coordinated activity of the striated penile muscles and is therefore not entirely determined by sexual motivation (Agmo, 1999).

The expression of sexual responses is affected by both individual and genetic differences between males (Pattij et al., 2005) and by each male's particular sexual experience (Thor \& Flannelly, 1977) as well as the environment in which sexual experience is acquired (Ismail, Zhao, \& Pfaus, 2008). For example, sexually inexperienced males take longer to initiate copulation in the presence of a sexually receptive female, display more mounts without intromissions, and have longer ejaculation latencies compared with sexually experienced males (Pfauss \& Wilkins, 1995). Thus, sexual experience provides a degree of instrumental learning that appears to "fix" motor patterns into stable, although individual, baselines of copulatory response (Ismail et al., 2008). Those motor patterns depend critically on the genitosensory feedback provided by intromissions and ejaculations, since males that mount but do not intromit (following penile anesthesia) do not develop baseline rates of copulatory response in comparison with males that experience penile stimulation and ejaculatory reward (Whalen, 1961). Tenk, Wilson, Zhang, Pitchers and Coolen (2009) provided evidence suggesting that the sexual behavior of male rats has rewarding and reinforcing properties, showing that there is a hierarchy in rewarding sexual behavior, where ejaculation is the most rewarding component, and the rewarding incentive value related to other components of sexual behavior depends on prior sexual experience.

In addition, earlier studies made by our group and others revealed that experience facilitates the male rat's heterosexual and homosexual behavior (Habr-Alencar, Dias, Teodorov, \& Bernardi, 2006; Teodorov, Salzgeber, Felicio, Varolli, \& Bernardi, 2002) and decreases or eliminates related impairments (Pfaus et al., 1995; Taylor et al., 1996). Some aspects of sexual function, such as mounts and intromissions, can be modified by sexual experience. For example, sexual experience decreases the first mount and intromission latencies, the parameters related with previous learning (Cruz-Casallas, Nasello, \& Felício, 2000). However, parameters such as ejaculation latency, number of intromissions until ejaculation and post ejaculatory latency were not altered. Sexual experience improves some sexual parameters such as mount and intromission latencies without altering ejaculatory parameters (Cruz-Casallas et al., 2000). Also, experienced rats exposed to a female prior to testing showed decreased anxiety-like behavior in the open field, elevated plus maze and light-dark transition tasks, and showed increased plasma and hypothalamic testosterone and $3 \alpha$-diol as well as increased hippocampal testosterone (Edinger \& Frye, 2007). 
Thus, considering that depression is most prevalent in adult human beings with an active sexual life, the purpose of this study was to investigate if the longterm treatment with FLX would be less deleterious to sexually experienced rats than to sexually naïve ones.

\section{Methods}

\section{Subjects}

Male and female Wistar adult rats from the Faculty of Veterinary Medicine and Zootechny of the University of São Paulo were used. The University Animal Care Committee approved all aspects of the research herein reported. The animals were housed in polypropylene cages $(32 \times 40 \times 18 \mathrm{~cm})$ under controlled temperature $(22$ $\pm 2{ }^{\circ} \mathrm{C}$ ), with a $12: 12$ reverse light/dark schedule (lights on at 10:00 pm) and free access to food and water during all the experimental procedures. The animals used in this study were maintained in accordance with the guidelines from the Committee on Care and Use of Laboratory Animal Resources, National Research Council, USA.

\section{Drugs}

Fluoxetine $\mathrm{HCl}$ (Eli Lilly Co., Indianapolis, IN) was prepared daily. The drug was suspended in two drops of Tween 80 in $0.9 \%$ saline solution and orally administered at $1 \mathrm{ml} / \mathrm{Kg}$ volume. Saline solution $(0.9 \%)$ was prepared daily using two drops of Tween 80 and was employed as the control solution. Each animal received $10 \mathrm{mg} / \mathrm{kg}$ of FLX. The dose was based in previous reports by VegaMatuszcyk et al. (1998) and Habr-Alencar et al. (2006) showing that this dose reduces male sexual motivation and modifies male heterosexual behavior.

\section{Preparation of animals}

Nineteen individuals were maintained for 21 days in the reverse light/dark cycle room prior to starting the experiments. These animals were divided in two groups. One group was treated with $10 \mathrm{mg} / \mathrm{kg}$ FLX $(\mathrm{n}=9)$ and the other with $0.9 \%$ saline solution $(\mathrm{n}=10)$ during 28 days, at $11: 00 \mathrm{~h}$. During the experiments, the rats were maintained in the reverse light/dark cycle room (lights on at 10:00 pm).

\section{Sexual behavior}

On the $14^{\text {th }}$ (test 1 ), 21 $1^{\text {st }}$ (test 2) and $28^{\text {th }}$ (test 3) days, each rat from both groups was allowed to mount ovariectomized female rats brought into estrous by treatment with exogenous estradiol $(50 u \mathrm{~g} / \mathrm{kg} \mathrm{sc}, 54 \mathrm{~h}$ before the tests) and progesterone $(2.0 \mathrm{mg} / \mathrm{kg} \mathrm{sc}, 6 \mathrm{~h}$ before the tests). The female rats were tested for receptivity before being placed with a single male and were paired only twice in each test with different males (Figure 1). Groups of different females were used in each test.

Behavioral experiments always began $3 \mathrm{~h}$ after drug administration. The male sexual behavior was observed in a wooden cage $(56 \times 35 \times 31 \mathrm{~cm})$ with a moveable cover and frontal glass. A sawdust layer served as bedding. During observation, a $40 \mathrm{~W}$ infrared lamp provided room illumination.

First, the male rat was introduced in the cage for a period of five minutes for adaptation. Following this habituation period, the estrous female was dropped into the arena with the male rat. The following components of sexual behavior were recorded during a 40-min period: latency to first mount, intromission latency, number of mounts, number of intromissions and number of ejaculations. In order to evaluate the effects of sexual experience on these parameters, test 1 (male rat without sexual experience) is compared to tests 2 and 3 , in which the males had already had sexual experience.

\section{Statistics}

In all tests, data of sexual behavior parameters were analyzed by two-way ANOVA followed by the Bonferroni test. In all cases, results were considered significant when $\mathrm{p}<.05$.

\section{Results}

In the first test, when rats had no previous sexual experience, FLX treatment increased mount latency ( $p$ $<.05)$, but did not significantly affect the intromission latency $(\mathrm{p}=.13)$ and the number of mounts $(\mathrm{p}=.067)$ and intromissions $(\mathrm{p}=.47)$ over a period of $40 \mathrm{~min}$ (Table 1$)$.

Comparing all tests for both the treated and control groups, the two-way ANOVA showed that FLX treatment significantly affected the mount $[\mathrm{F}(1,51)=9.93, \mathrm{p}<.01]$ and intromission latencies $[\mathrm{F}(1,51)=7.53, \mathrm{p}<.01]$, as well as the number of intromissions $[\mathrm{F}(1,51)=4.45, \mathrm{p}<$ $.05]$, but did not affect the number of mounts $[\mathrm{F}(1,51)=$

Table 1. Effects of long-term FLX administration on male rats' sexual behavior during the first testing day. Data are presented as means \pm S.E.M. $\mathrm{s}=$ seconds; $(\mathrm{n})=$ number of animals per group.

\begin{tabular}{lcc}
\hline \multirow{2}{*}{ Parameters } & \multicolumn{2}{c}{ Groups } \\
\cline { 2 - 3 } & & Control \\
Mount latency $(\mathrm{s})$ & $136.30 \pm 31.47$ & $261.33 \pm 48.82 *$ \\
& $(\mathrm{n}=10)$ & $(\mathrm{n}=9)$ \\
Intromission latency $(\mathrm{s})$ & $528.63 \pm 144.60$ & $852.60 \pm 145.31$ \\
& $(\mathrm{n}=10)$ & $(\mathrm{n}=9)$ \\
Number of mounts & $36.60 \pm 5.20$ & $23.56 \pm 4.00$ \\
& $(\mathrm{n}=10)$ & $(\mathrm{n}=9)$ \\
Number of intromissions & $13.00 \pm 3.18$ & $10.22 \pm 2.15$ \\
& $(\mathrm{n}=10)$ & $(\mathrm{n}=9)$ \\
Number of ejaculations & $1.60 \pm 0.40$ & $1.33 \pm 0.33$ \\
& $(\mathrm{n}=10)$ & $(\mathrm{n}=7)$ \\
\hline
\end{tabular}

$* \mathrm{p}<.05$ in relation to the control group (Student's $t$-test). 


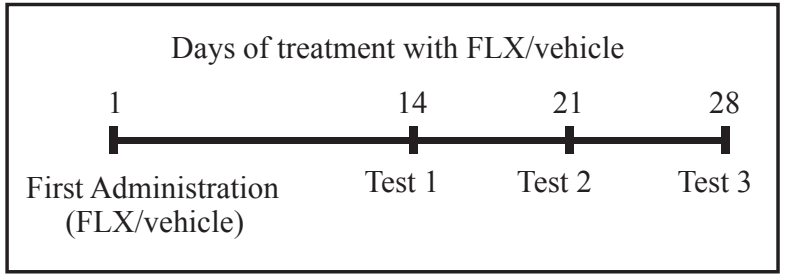

Figure 1. Diagram of the experimental design.

$0.16, p=.69]$ and ejaculations $[F(1,51)=1.47, p=.23]$ in the 40-min period. The post-hoc comparison revealed that FLX treatment significantly increased mount latency in the first testing day while also increasing the intromission latency and decreasing the number of intromissions in the third test, as compared to the control group (Figure 2).

In the control group, the two-way ANOVA showed that sexual experience acquired in the three tests significantly affected the results of mount latency $[F(2,51)=26.16, p<.001]$, intromission latency $[\mathrm{F}(2,51)=10.61, \mathrm{p}<.001]$ and number of mounts $[\mathrm{F}(2,51)=4.26, \mathrm{p}<.05]$. Post-hoc comparisons revealed that sexual experience decreased the mount latency in both the control and treated groups on tests 2 and 3 . In these two tests, the difference between the groups observed in test 1 disappeared. Sexual experience also decreased the intromission latency on tests 2 and 3 gradually, when compared to the first testing day. In the FLX-treated group, a decrease was observed that only reached statistical difference on the third test. The number of mounts was significantly increased in the FLX-treated group in the third test, while the control group was not affected. Finally, sexual experience did not significantly increase the number of intromissions in the treated group, but increased this parameter in the control group. Besides, a difference between the two groups appeared in the third test (Figure 2).

\section{Discussion}

SSRIs are known to induce delayed orgasm and ejaculation, while their effect on other aspects of the sexual function, such as sexual motivation, arousal, and erectile function, are unclear (Sukoff et al., 2008). The present results provide further evidence for slight inhibitory effects of long-term treatment with FLX on the sexual behavior of male rats as the FLX treatment increased only the mount latency. Sexual experience per se improved the control rats' sexual behavior. The FLX-treated group also showed facilitating effects of sexual experience, though not to the same extent as in the control group. The number of mounts and intromissions in FLX-treated rats increased in the final test, while the number of ejaculations decreased.

As previously described, both mount and intromission latencies are measures of sexual
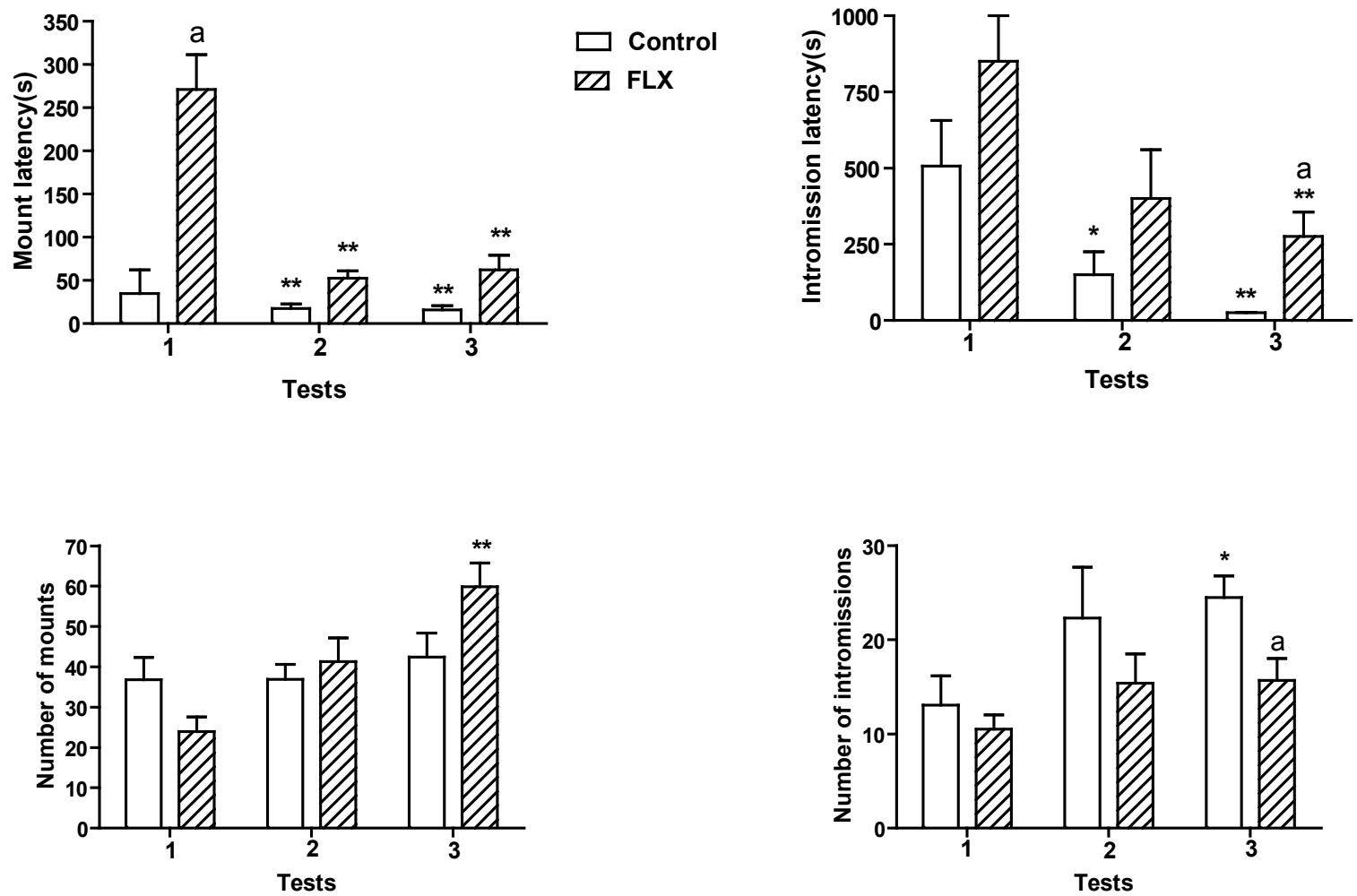

Figure 2. Effects of sexual experience on the rats' sexual parameters in the long-term treatment with FLX or vehicle. The parameters are presented as means \pm S.E.M. Control group $\mathrm{n}=10$; experimental group $\mathrm{n}=9$. $* \mathrm{p}<.05$ compared to respective group in the first testing day; ${ }^{*} \mathrm{p}<.01$ compared to respective group in the first testing day; ap $<.05$ compared to control group in respective testing day. Two way ANOVA followed by the Bonferroni test. 
motivation. Intromission latency requires penile erection and coordinated activity of the striated penile muscles and is therefore not entirely determined by sexual motivation (Agmo, 1999). During the first session, FLX only increased mount latency suggesting that FLX long-term exposure only modified rats' sexual motivation after 14 days and not penile erection.

The number of mounts also reflects sexual motivation. However, it may be mistaken for other intervenient factors and should be interpreted with caution (Agmo, 1997). In this respect, FLX-treated animals did not show differences in the first session in the mount and intromission numbers; these parameters, however, were increased in the final period of treatment (28 days), suggesting that the motor aspects of sexual behavior might have been affected by FLX long-term treatment. In this regard evidence shows that, in male rats, the acute administration of FLX results in sexual behavior inhibition evidenced by prolonged ejaculation latency and/or by increased number of mounts and/or intromissions exhibited prior to ejaculation (Baum et al., 1980; Yells et al., 1992, 1994, 1995).

FLX $(0.75 \mathrm{mg} / \mathrm{kg})$ administered during 28 days did not modify the proneness of male rats to stay closer to female rats; however, the copulatory pattern was altered in FLX-treated rats, who exhibited longer latencies of intromission (Taylor et al., 1983). Other researches showed that FLX (10 mg/kg; 13 and 28 days) inhibited the copulatory pattern by increasing the latency to ejaculation and the frequency of mounts. Therefore, FLX reduced the apparent motivation of the male rat to pursue an estrous female based on the amount of time the male spent close to the female rat (VegaMatuszcyk et al., 1998). In our case, FLX treatment significantly decreased the number of intromissions while increasing the number of mounts after 28 days from administration. This was possibly due to the fact that the long-term treatment with FLX interferes with rats' sexual erectile or motor processes, but the lack of alterations in the number of ejaculations does not support this hypothesis.

Previous research demonstrated that sexual experience alters sexual behavior (Agmo, 1976; Agmo \& Pickler, 1989; Borg, Esbenshade, Johnson, Lunstra, \& Ford, 1992; Mitchell \& Stewart, 1989; Pfaus et al., 1995; Taylor et al., 1996). The influence of classical (Pavlovian) conditioning in the sexual behavior of rats (Tenk et al., 2009) and its importance for human sexual problems have already been studied (Cutmore \& Zamble, 1988; Larsson, 1956; Zamble, Hadag, Mitchell, \& Cutmore, 1985, 1986).

Zamble et al. $(1985,1986)$ demonstrated that sexual response can be conditioned as shown by decreases in the time to complete copulation during postconditioning conditioned stimulus (CS) tests. Tenk et al. (2009) studied the rewarding values of the different components of sexual behavior. They showed that there is a hierarchy of rewarding sexual behavior, with ejaculation being the most rewarding component, and that the rewarding incentive value of other components of sexual behavior is dependent upon prior sexual experience.

Cutmore and Zamble (1988) investigated the effects of Pavlovian conditioning in male rats that did not reach ejaculation with a receptive female on a pretest. These rats were randomly assigned to one of two groups: CSUS paired or CS-US unpaired. The CS consisted of a period of placement in a running wheel which allowed measurement of incidental activity. The US was (arousing) exposure to a female separated from the male by a wire mesh screen. Subjects in the paired group were significantly more likely to achieve ejaculation on the CS test than those in the control group, and they were also more active during the test. In contrast, differences on the No-CS test were not significant, consistent with expectations from a Pavlovian explanation. These data show the efficacy of Pavlovian procedures in improving sexual performance, with a possible application to increase arousal to selected cues for human subjects, e.g., some individuals with erectile dysfunction.

Sexual experience improves sexual behavior by decreasing the first mount and first intromission latencies, which can be related to previous learning (Cruz-Casallas, Nasello, \& Felício, 2000; Habr-Alencar et al., 2006; Tenk et al., 2009; Teodorov et al., 2002). However, parameters such as ejaculation latency, number of intromissions until ejaculation and post ejaculatory latency were not altered. Therefore, to evaluate the influences of sensory or chemical stimuli on behavior, experimental and control animals must be exposed to the same number of training sessions (Nasello, Vanzeler, Madureira, \& Felício, 1997). Sexual experience may mask facilitating influences on this behavior, and it is thus important to know whether the tested animals had any previous sexual experience. On the other hand, training experience, by decreasing latencies and variability, may reveal disruptive influences (Holloway \& Domjan, 1993).

According to our results, sexual experience per se gradually reduced the latencies related to sexual behavior in all tests. The mount and ejaculation rates were increased in the last session, whereas the number of intromissions remained similar to that of the control group in the first and second testing sessions. The decreased latencies reveal an intrinsic learning dependent on the number of sessions that were repeated for several weeks in the same experimental conditions. Moreover, the decreases in mount and intromission latencies showed a clear improvement in experienceinduced quantitative improvements regarding the sexual motivation that is positively related to the number of sessions. Finally, sexual experience only attenuates the damage promoted by FLX during the sessions, except in what concerns the number of mounts. 


\section{Acknowledgements}

This research report is part of the paper submitted by Soraya Ferreira Habr to the Biomedical Sciences Institute of the University of São Paulo, Brazil, as a requirement for the award of the degree of Master of Sciences (Pharmacology Department). The research was supported by a fellowship from the Conselho Nacional de Desenvolvimento Científico e Tecnológico-CNPQ(NationalCouncilofScientific and Technological Development - Proc.133808/2003-3). Special thanks to Kate Karelina (University of Richmond) and Brand Rima (University of Richmond) for expert technical assistance.

\section{References}

Agmo, A. (1976). Cholinergic mechanisms and sexual behavior in male rabbits. Psychopharmacology, 1, 43-45.

Agmo, A., \& Picker Z. (1989). Catecholamines and the initiation of sexual behavior in male rats without sexual experience. Pharmacology Biochemistry and Behavior, 35, 327-334.

Agmo, A. (1997). Male rat sexual behavior. Brain Research Protocols, 1, 203-209.

Agmo, A. (1999). Sexual motivation - an inquiry into events determining the occurrence of sexual behavior. Behavioral Brain Research, 105, 129-150.

Ahlenius, S., Eriksson, H., Larsson, K., Modigh, K., \& Södersten, P. (1971). Mating behavior in the male rat treated with p-chlorophenylalanine methyl ester alone and in combination with pargyline. Psychopharmacologia, 20, 383-388.

Ahlenius, S., Heimann, M., \& Larsson, K. (1979). Prolongation of the ejaculation latency in the male rat by thioridazine and chlorimipramine. Psychopharmacology (Berlin), 65, 137-140.

Althof, S.E., Levine, S.B., Corty, E.W., Risen, C.B., Stern, E.B., \& Kurit, D.M.(1995). A double-blind crossover trial of clomipramine for rapid ejaculation in 15 couples. Journal of Clinical Psychiatry, $56,402-407$.

Balon R. (1995). Fluoxetine and sexual dysfunction. Journal of the American Medical Association, 273, 1489-1490.

Balon R. (2006). SSRI-associated sexual dysfunction. American Journal of Psychiatry, 163, 1504-1509.

Baum, M.J., \& Starr, M.S. (1980). Inhibition of sexual behavior by dopamine antagonist or serotonin agonist drugs in castrated male rats given estradiol or dihydrotestosterone. Pharmacology Biochemistry and Behavior, 13, 57-67.

Borg, K.E., Esbenshade, K.L., Johson, B.H., Lunstra, D.D., \& Ford, J.J. (1992). Effects of sexual experience, season, and mating stimuli on endocrine concentrations in the adult rat. Hormones and Behavior, 26, 87-109.

Cruz-Casallas, P.E., Nasello, A.G., \& Felício, L.F. (2000). A quantitative analysis of the role of experience in the regulation of sexual behavior in male rats Psychobiology, 28, 406-410.

Cutmore, T.R., \& Zamble, E.A. (1998). Pavlovian procedure for improving sexual performance of noncopulating male rats. Archives of Sexual Behavior, 17, 371-380.

Dannon, P.N., Iancu, I., Lowengrub, K., Gonopolsky, Y., Musin, E., Grunhaus, L., \& Kotler, M. (2007). Anaturalistic long-term comparison study of selective serotonin reuptake inhibitors in the treatment of panic disorder. Clinical Neuropharmacology, 30, 326-334.

Da Prada, M., Carruba, M., O’Brien, R.A., Saner, A., \& Pletscher, A. (1972). The effect of 5,6-dihydroxytryptamine on sexual behaviour of male rats. European Journal of Psychopharmacology, 19, 288-290.

Edinger, K.E., \& Frye, C.A. (2007). Sexual experience of male rats influences anxiety-like behavior and androgen levels. Physiology \& Behavior, 92, 443-453.

Frank, J.L.W., Hendricks, S.E., \& Olson, C.H. (2000). Multiple ejaculations and chronic fluoxetine: effects on male rat copulatory behavior. Pharmacology Biochemistry and Behavior, 66, 337-342.

Gamaro, G.D., Prediger, M.E., Lopes J., Bassani, M.G., \& Dalmaz, C. (2008). Fluoxetine alters feeding behavior and leptin levels in chronically-stressed rats. Pharmacology Biochemistry and Behavior, 90, 312-317.

Gartlehner, G., Gaynes, B.N., Hansen, R.A., Thieda, P., DeVeaughGeiss, A., Krebs, E.E., Moore, C.G., Morgan, L., \& Lohr K.N. (2008). Comparative benefits and harms of second-generation antidepressants: background paper for the American College of Physicians. Annals of Internal Medicine, 149, 734-50.

Habr-Alencar, S.F., Dias, R.D., Teodorov, E., \& Bernardi, M.M. (2006). The effect of hetero-and homosexual experience and longterm treatment with fluoxetine on homosexual behavior in male rats. Psychopharmacology, 189, 269-275.

Hay, PJ. (2007).Understanding bulimia. Australian Family Physician, 36, 708-712.

Holloway, K.S., \& Domjan, M. (1993). Sexual approach conditioning: tests of unconditioning stimulus devaluation using hormones manipulations. Journal of Experimental Psychology: Animal Behavior Processes, 19, 7-55.

Hsiao, S.H, Chung, H.H, Tong, Y.C, \& Cheng, J.T. (2006). Chronic fluoxetine administration desensitizes the hyperglycemia but not the anorexia induced by serotonin in rats receiving fructoseenriched chow. Neuroscience Letters, 404 (1-2), 6-8.

Ismail, N., Zhao, Y., \& Pfaus, J.G. (2008). Context-dependent acquisition of copulatory behavior in the male rat: role of female availability. Behavioral Neuroscience, 122, 991-997.

Larsson, K. (1956). Conditioning and sexual behavior in the male albino rat. Stockholm: Almqvist \& Wiksell.

Leombruni, P., Pierò, A., Lavagnino, L., Brustolin, A., Campisi, S., \& Fassino, S.A. (2008). Randomized, double-blind trial comparing sertraline and fluoxetine 6-month treatment in obese patients with Binge Eating Disorder. Progress in Neuro-Psychopharmacology \& Biological Psychiatry, 32, 1599-1605.

Madeo, B., Bettica, P., Milleri, S., Balestrieri, A., Granata, A.R.M., Carani, C., Rochira, V. (2008). The effects of citalopram and fluoxetine on sexual behavior in healthy men: evidence of delayed ejaculation and unaffected sexual desire. A randomized, placebocontrolled, double-blind, double-dummy, parallel group study. Journal of Sexual Medicine, 5, 2431-2441.

Mancini, M.C., \& Halpern, A. (2006). Pharmacological treatment of obesity. Arquivos Brasileiros de Endocrinologia e Metabologia, 50, 377-389.

Maswood, N., Sarkar, J., \& Uphouse, L. (2008). Modest effects of repeated fluoxetine on estrous cyclicity and sexual behavior in Sprague Dawley female rats. Brain Research, 1245, 52-60.

Mendels, J., Camera, A., \& Sikes, C. (1995). Sertraline treatment for premature ejaculation. Journal of Clinical Psychopharmacology, $15,341-346$

Mitchell, JB., \& Stewart, J. (1989). Effects of castration, steroid replacement, and sexual experience on mesolimbic dopamine and sexual behaviors in the male rat. Brain Research, 491, 116-127.

Mitchell, J.E, de Zwaan, M., \& Roerig, J.L. (2003). Drug therapy for patients with eating disorders. Current Drug Targets - CNS \& Neurological Disorders, 2, 17-29.

Montejo-Gonzalez, A.L., Llorca, G., Izquierdo, J.A., Ledesma, A., Bousono, M., Calcedo, A., Carrasco, J.L., Ciudad, J., Daniel, E., De la Gandara, J., Derecho, J., Franco, M., Gómez, M.J., Macias, J.A., Martin, T., Perez, V., Sanchez, J.M., Sanchez, S., \& Vicens, E. (1997). SSRI-induced sexual dysfunction: fluoxetine, paroxetine, sertraline, and fluvoxamine in a prospective, multicenter, and descriptive clinical study of 344 patients. Journal of Sex \& Marital Therapy, 23, 176-194.

Montejo, A.L., Llorca, G., Izquierdo, J.A., Rico-Villademoros, F. (2001). Incidence of sexual dysfunction associated with antidepressant agents: a prospective multicenter study of 1022 outpatients. Spanish Working Group for the Study of Psychotropic-Related Sexual Dysfunction. Journal of Clinical Psychiatry, 62, 10-21.

Montgomery, S.A., Baldwin, D.S., Riley, A. (2002). Antidepressant medications: a review of the evidence for druginduced sexual dysfunction. Journal of Affective Disorders, 69, 119-140.

Nasello, A.G., Vanzeler, M.L.A, Madureira, E.H., \& Felício, L.F. (1997). Effects of acute and long-term domperidone treatment on prolact and gonadal hormone levels and sexual behavior of male and female rats. Pharmacology Biochemistry and Behavior, 58, 1089-1094.

Patterson, W.M. (1993). Fluoxetine-induced sexual dysfunction. Journal of Clinical Psychiatry, 54, 71.

Pattij, T., de Jong, T.R., Uitterdijk, A., Waldinger, M.D., Veening, J.G., Cools, 
A.R., van der Graaf, P.H., \& Olivier, B. (2005). Individual differences in male rat ejaculatory behaviour: searching for models to study ejaculation disorders. European Journal of Neuroscience, 22, 724-34.

Pfaus, J.G., \& Wilkins, M.F. (1995). A novel environment disrupts copulation in sexually naive but not experienced male rats: reversal with naloxane. Physiology \& Behavior, 57, 1045-1049.

Placidi, R.J., Chandler, P.C., Oswald, K.D., Maldonado, C., Wauford, P.K., Boggiano M.M. (2004). Stress and hunger alter the anorectic efficacy of fluoxetine in binge-eating rats with a history of caloric restriction. International Journal of Eating Disorders, 36, 328-41.

Sachs, B.D., \& Meisel, R.L. (1979). Pubertal development of penile reflexes and copulation in male rats. Psychoneuroendocrinology, 4, 287-296.

Sarkar, J., Hiegel, C., Ginis, G.E., Hilbun, E., \& Uphouse, L. (2008). Subchronic treatment with fluoxetine attenuates effects of acute fluoxetine on female rat sexual behavior. Brain Research, 1190, 56-64.

Segraves, R.T., Saran, A., Segraves, K., \& Maguire, E. (1993). Clomipramine versus placebo in the treatment of premature ejaculation: a pilot study. Journal of Sex \& Marital Therapy, 19, 198-200.

Sukoff, B., Bettica, P., Milleri, S., Balestrieri, A., Granata, A.R., Carani, C., Rochira, V. (2008). The effects of citalopram and fluoxetine on sexual behavior in healthy men: evidence of delayed ejaculation and unaffected sexual desire. A randomized, placebocontrolled, double-blind, double-dummy, parallel group study. Journal of Sexual Medicine, 11, 2431-2441.

Tagliamonte, A., Tagliamonte, P., Gessa, G.L. (1971). Reversal of pargyline-induced inhibition of sexual behaviour in male rats by p-chlorophenylalanine. Nature 230, 244-245.

Tagliamonte, A., Tagliamonte, P., Gessa, G.L., \& Brodie, B.B. (1969). Compulsive sexual activity induced by p-chlorophenylalanine in normal and pinealectomized male rats. Science, 166, 1433-1435.

Taylor, G.T., Weiss, J., \& Komitowsky, D. (1983). Reproductive physiology and penile papillae morphology of rats after sexual experience. Journal of Endocrinology, 98, 155-163.

Taylor, G., Bardgett, M., Csernansky, J., Early, T., Haller, J., Scherrer, J., \& Womack, S. (1996). Male reproductive systems under chronic fluoxetine or trimipramine treatment. Physiology \& Behavior, 59, 479-485.

Teodorov, E., Salzgeber, S.A., Felício, L.F., Varolli, F.M.F., \& Bernardi, M.M. (2002). Effects of perinatal picrotoxin and sexual experience heterosexual and homosexual behavior in male rats. Neurotoxicology and Teratology, 24, 235-245.
Tenk, C.M., Wilson, H., Zhang, Q., Pitchers, K.K., Coolen, L.M (2009).Sexual reward in male rats: effects of sexual experience on conditioned place preferences associated with ejaculation and intromissions. Hormones and Behavior, 55, 93-97.

Toates, F.M. (1986). Motivational systems. Cambridge, UK: Cambridge University Press.

Thor, D., \& Flannelly, K.J. (1977). Social-olfactory experience and initiation of copulation in the virgin male rat. Physiology \& Behavior, 19, 411-417.

Uphouse, L., Hensler, J.G., Sarkar, J., \& Grossie, B. (2006). Fluoxetine disrupts food intake and estrous cyclicity in Fischer female rats. Brain Research, 1072, 79-90.

Vega-Matuszcyk, J., Larsson, K., \& Eriksson, E. (1998). The selective serotonin reuptake inhibitor fluoxetine reduces sexual motivation in male rats. Pharmacology Biochemistry and Behavior, 60, 527-532.

Waldinger, M.D., \& Olivier, B. (1998). Selective serotonin reuptake inhibitor-induced sexual dysfunction: clinical and research considerations. International Clinical Psychopharmacology, $13,527-533$.

Whalen, R.E. (1961). Effects of mounting without intromission and intromission without ejaculation on sexual behavior and maze learning. Journal of Comparative and Physiological Psychology, 54, 409-415.

Yells, D.P., Prendergast, M.A., Hendricks, S.E. (1992). Lesions of the nucleus paragigantocellularis: effects on mating behavior in male rats. Brain Research, 596, 73-79.

Yells, D.P., Prendergast, M.A.,Hendricks, S.E., \& Nakamura, M.(1994). Fluoxetine-induced inhibition of male rat copulatory behavior: modification by lesions of the nucleus paragigantocellularis. Pharmacology Biochemistry and Behavior, 49, 121-127.

Yells, D., Prendergast, M.A., Hendricks, S.E., \& Miller, M.E. (1995). Monoaminergic influences on temporal patterning of sexual behavior in male rats. Physiology \& Behavior, 58, 847-852.

Zamble, E., Hadag, G.M., Mitchell, J.B., \& Cutmore, T.R. (1985). Pavlovian conditioning of sexual arousal: first and second-order effects. Journal of Experimental Psychology: Animal Behavior Processes, 11, 589-610.

Zamble, E., Mitchell, J.B., \& Findlay, H. (1986). Pavlovian conditioning of sexual arousal: parametric and background manipulations. Journal of Experimental Psychology: Animal Behavior Processes, 12, 403-411. 